\title{
Prevalence of Salmonella Spp Isolated from Poultry Products (Carcasses and Eggs) from Markets and Slaughterhouses of Bamako
}

\author{
Brahima Sacko ${ }^{1,2, *}$, Satigui Sidibe ${ }^{2}$, Modibo Kouyate ${ }^{1}$, Oumar Traore ${ }^{2}$, Ibrahim Sow ${ }^{1,2}$, \\ Kadiatou Coulibaly ${ }^{2}$, Amadou Hamadoun Babana 1 \\ ${ }^{1}$ Department of Biology, Faculty of Science and Technology, University of Science, Techniques and Technology, Bamako, \\ Mali \\ ${ }^{2}$ Diagnostic and Research Service, Central Veterinary Laboratory, Bamako, Mali
}

\author{
Email address: \\ sackobrahima29@gmail.com (B. Sacko), sidibsatigui@gmail.com (S. Sidibe), djelibam@yahoo.fr (M. Kouyate), \\ Oumarsaly62@yahoo.fr(O. Traore), sowbreham@gmail.com (I. Sow), welecoulibaly@yahoo.fr (K. Coulibaly), \\ ahbabana@laborem-biotech.com (A. H. Babana) \\ "Corresponding author
}

\section{To cite this article:}

Brahima Sacko, Satigui Sidibe, Modibo Kouyate, Oumar Traore, Ibrahim Sow, Kadiatou Coulibaly, Amadou Hamadoun Babana. Prevalence of Salmonella Spp Isolated from Poultry Products (Carcasses and Eggs) from Markets and Slaughterhouses of Bamako. American Journal of Biomedical and Life Sciences. Vol. 7, No. 6, 2019, pp. 179-183. doi: 10.11648/j.ajbls.20190706.19

Received: November 17, 2019; Accepted: December 17, 2019; Published: December 23, 2019

\begin{abstract}
In Mali, poultry farming is a valuable source of income for the population. With huge production potential, the conditions necessary to achieve the quality and safety of poultry products must be in place. This study, conducted between February 2017and May2018 had the objective of assessing the bacteriological prevalence of salmonella in eggs and poultry carcasses slaughtered in the district of Bamako. It focused on analyzing carcasses384 and112 eggs collected from poultry at markets and slaughterhouses. The individual samples were first sown on medium preenrichment and on enrichment media followed by isolation of the bacteria on selective media and identification by biochemical tests. Work has established a global prevalence of bacteriological $12,90 \%$ which varied depending on the type of poultry forhens $14.91 \%$ against $10.88 \%$ guinea fowl, the nature of the sample (eggs $(09,82 \%)$ and carcasses $(13.80 \%)$ and the sampling site (the more was observed at Niamakoro monitoring Boulkassoumbougou and Hamdallaye).
\end{abstract}

Keywords: Prevalence, Salmonella, Poultry, Bamako

\section{Introduction}

Since many years Salmonella is the major cause of the human digestive tract infections associated with the consumption of food of animal origin. Among these products, poultry meat and eggs are heavily involved. Despite the efforts of producers, the contamination rate of live poultry Salmonella is still very high. The serotype Enteritidis is currently the most widespread in the poultry sector [11]. Salmonella can be case managers of food poisoning in humans. However poultry meat and eggs are likely to be a source of pathogenic microorganisms in general and especially Salmonella. In Mali food borne diseases are poorly understood and are not subject to mandatory reporting. Typhoid fever annually kills nearly500000 children under 5years and affects $0.5 \%$ of the world population, Fofana [1]. The World Health Organization (WHO) [13] reports nearly 17 million annual cases of typhoid fever 600000 deaths, Fofana [1] according to the source, contamination of food is involved in $90 \%$ of cases of typhoid fever [14]. The meat contamination by Salmonella is a public health problem $[16$, $10]$ and poultry products are often regarded as the cause of certain epidemics $[2,17]$. Other salmonella prevalence studies were made in Mali. Thus following the analysis of 
eggs from Bamako, an infection rate of $7.87 \%$ (20 positive/254 tested) were obtained by Sidibe [6]. A study on the evaluation of risks associated with the presence of salmonella in eggs from breeding improved the suburban area of Bamako district during the period 2008-2009 has followed through bacteriological analysis a prevalence of $11.79 \%$ (23positive/195cloacal swabs tested) and $5.76 \%$ (03positive/52 eggs tested). Sidibe [6]. Thus, a joint study by the ANSSA and LCV in some modern poultry farms in the Bamako district and its suburban area yielded bacteriological prevalence rates respectively of $15.38 \%$ (both positive cloacal swabs of 11 cultured) in a breeding poultry breeding. According to the same study, the rate was $13.84 \%$ (18 positive swabs cultured on130 tested).

\section{Material and Methods}

\subsection{Biological Material}

As biological material we used essentially the organs and poultry eggs.

\subsection{Methods}

The approach combined the one hand, investigations survey, and also laboratory sampling and analysis.

\subsubsection{Investigation Field}

\section{Study zone}

The study was conducted in urban areas of Bamako. Our choice reflects the importance of slaughterhouses and poultry markets.

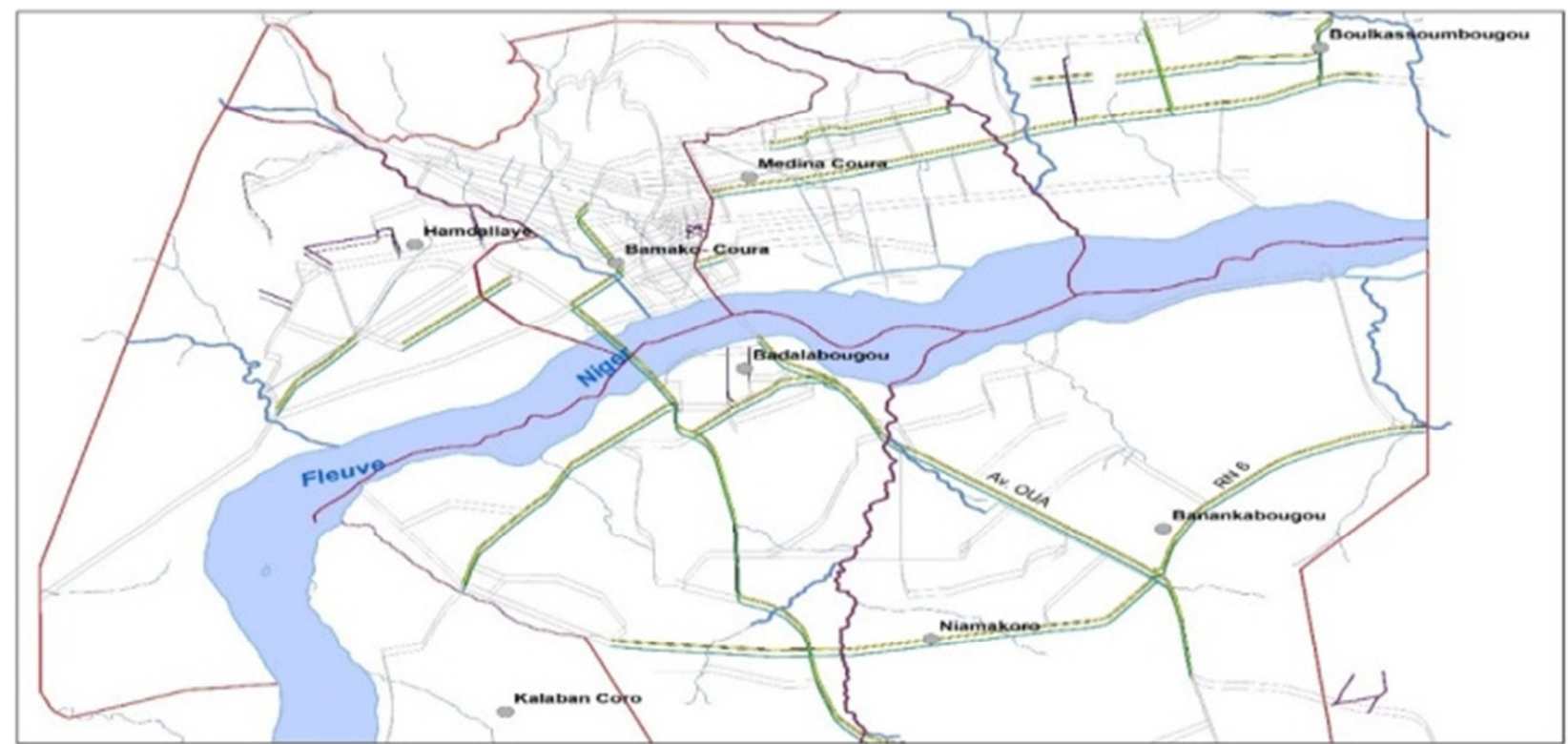

Figure 1. Location differents ampling sites.

\section{Sampling and collection}

Our sampling has affected 08 poultry markets. It was made randomly.384carcasses and112eggs were bought at the poultry markets. The sampling equipment was constituted by a cooler with ice serving as a source of cold at the time of transportation, a batch of plastic bags for packaging and a label for the identification of batches. The carcasses are placed under windows and chimneys in central veterinary laboratory.

\subsubsection{Type and Study Period}

This is an exploratory study which took place during the period from February 2017 to May2018.

Preparation of the sample to the laboratory

Whole shell eggs are opened aseptically: after rapid washing with water, the egg is cleaned with alcohol and then the shell is opened in steriles calpel. The interior of the egg is collected using a sterile pipette or is directly poured into a sterile container. Each egg is removed $05 \mathrm{ml}$, trying as possible to both the yellow as white.

Experimental protocol
The samples were first seeded on to liquids (Tetrathionate broth and Rappaport broth) incubated in an oven at $37^{\circ} \mathrm{C}$ for 24h. On the second day, there shall be sowing on solid media (Mac Conkey agar and agar Salmonella Shigella) cultures obtained on liquid media. Then Salmonella suspect colonies appeared on the agar are transplanted on tryptic soy agar to obtain pure cultures. The pure cultures obtained on tryptic soy agar are transplanted on classic Identification media for biochemical identification.

\subsubsection{Data Analysis}

Data were entered in Excel 2010 and statistical analysis was done with the software SPSS.20. To compare the values of different variables, we used the chi 2 test both Pearson at probability level $\mathrm{p}=5 \%$.

\section{Results}

\subsection{Survey Data}

Information obtained from the survey sheet, were used to 
determine the main factors favoring the contamination of carcasses and poultry eggs by Salmonella in slaughterhouses and markets. The results of these investigations are shown in Table 1.

Table 1. Poultry market characteristics.

\begin{tabular}{lll}
\hline Indicators & Market $\mathbf{N = 8 )}$ & Percentage (\%) \\
\hline Bare ground & 7 & 87,5 \\
Almost home & 8 & 100 \\
Vermin & 5 & 62,5 \\
Temporary site & 4 & 50 \\
Cleaning market & 0 & 0 \\
Nearly garbage dump & 3 & 37,5 \\
\hline
\end{tabular}

Table 2. Hygiene in poultry slaughterhouses.

\begin{tabular}{lll}
\hline Indicators & $\begin{array}{l}\text { Slaughterhouses } \\
(\mathbf{N}=\mathbf{8})\end{array}$ & $\begin{array}{l}\text { Percentage } \\
(\%)\end{array}$ \\
\hline Renewal of scalding (1time per day) & 3 & 37,5 \\
Renewal of scalding (2 time per day) & 0 & 0 \\
Cleaning surfaces (walls, bench, floor) & 1 & 12,5 \\
Open Installation & 8 & 100 \\
Covered building & 0 & 0 \\
Nearly garbage dump & 2 & 25 \\
\hline
\end{tabular}

\subsection{Prevalence of Contamination by Salmonella Spp}

Salmonella prevalence varied according to the poultry species, the nature of the levy and provenance. The results obtained from the analysis of our samples are given in the following tables.

Prevalence of Salmonella based on the species

Table3. Frequency of salmonella according to the species.

\begin{tabular}{llll}
\hline Poultry species & Negative & positive & p-value \\
\hline Guinea fowl & 221 & 27 & \\
Hen & 211 & 37 & 0,02 \\
Total & 432 & 64 & \\
\hline
\end{tabular}

From the analysis of the results of Table 3 shows that the 496 samples tested, 64 gave positive cultures of salmonella $(12.90 \%)$. The highest infection rate was observed in the case hen $(14.91 \%)$ against $10.88 \%$ for the species guinea fowl.

The results showed that the salmonella prevalence varies significantly depending on the species $(p<0.05)$.

Salmonella prevalence depending on the type of sample

Table4. Frequency of salmonella according to the nature of the levy.

\begin{tabular}{llll}
\hline Nature of sampling & Negative & Positive & p-value \\
\hline Egg & 101 & 11 & \\
Organ & 331 & 53 & 0,3 \\
Total & 432 & 64 & \\
\hline
\end{tabular}

Analysis of the results of table 4 indicates 11 eggs $(09,82 \%)$ and 53 carcasses $(13.80 \%)$ had positive cultures of Salmonella.

The results showed that the prevalence of salmonella does not vary significantly according to the type of sample $(\mathrm{p}>0.05)$.

Prevalence of salmonella according to the source specimen.

Table5. Frequency of salmonella according to the source specimen.

\begin{tabular}{llll}
\hline Origin & Negative & Positive & p-value \\
\hline Badalabougou & 62 & 0 & \\
Hamdallaye & 49 & 13 & \\
Niamakoro & 48 & 14 & \\
Banankabougou & 60 & 2 & 0,001 \\
Boulkassoumbougou & 49 & 13 & \\
Bamako-coura & 55 & 7 & \\
Médina-coura & 52 & 10 & \\
Kalabancoro & 57 & 5 & \\
\hline
\end{tabular}

From the analysis of the results of table5 shows that the contamination rate as was observed Niamakoro monitoring Boulkassoumbougou and Hamdallaye. Samples from Badalabougou all gave negative cultures of salmonella.

The results showed that the salmonella prevalence varies significantly depending on the nature of the sample $(\mathrm{p}<0.05)$.

\section{Discussion}

\subsection{Survey Data}

Visited poultry markets generally have the same characters. They are driven every day, and are mostly supplied by animals from local farms. Some animals in these markets are imported from different parts of the country and even outside. These markets are flooded with different poultry species. Unfortunately, the outlets are rarely or poorly constructed according to the standards of hygiene and sanitation. That is the conclusion that has been done Fofana [1], in his study on Assessment of contamination of typhoid fever caused by the consumption of food sold in the streets of Bamako district Affected poultry are broiler chickens, guinea fowl and chickens traditional. A common feature of these markets is the presence of pests such as mice.

The studied poultry markets are 50\% located on temporary sites, and are also poorly maintained and very little developed. These markets are located near landfills (37.50\%) they often are located near homes, which could be a source of unhealthy and pollution for people because manure odors and gas emissions to atmosphere. The lack of cleaning of surfaces and the no renewal of scalding water for most slaughterhouses favor carcass contamination.

\subsection{Prevalence of Salmonella}

This study established a Salmonella prevalence of $12,90 \%$ in poultry products (eggs and carcasses). This rate is comparable to that achieved by the European Union [2] in Spain was $12.2 \%$ and higher than that obtained by Sidibe [6] in Mali and in Tchad by Hamadou [5]. This significant prevalence could be explained by the epizootic situation of 
salmonella on farms; poultry bad transport conditions to slaughter areas and slaughtering conditions of poultry and hygiene slaughter websites. Van Immerseel [7] and ELGROUD [8] have shown that infected poultry in livestock are a major source of spreading salmonella, during the various stages of processing. Thus the prevalence of contaminated carcasses is always higher than the live chickens. According to Brewer PH [3] and WHO [12] in poultry industry, once a contaminated batch is introduced into the slaughter, it is difficult to prevent contamination of other animals because of the high level of contamination across all facilities. The prevalence observed in chicken and guinea fowl species were respectively $14.91 \%$ and $10.88 \%$. This result is explained by poor breeding conditions for hens. The prevalence of Salmonella observed in eggs and carcasses were respectively $09.82 \%$ and $13.80 \%$ carcasses. Contamination of eggs at the markets is due to the poor conditions of transport and storage. Most eggs are transported in vans or motorcycles three wheels not refrigerated and stored at the shops at room temperature. Note also that eggs are put on sale in deplorable conditions as they are exposed to the sun all day. This contamination can also be explained by several factors: overcrowding leads to high production of faeces and an increase in the ambient temperature of the premises favorable for microbial growth, poor hygiene of premises and equipment promotes persistence salmonella in dust, ambient air and at the nesting surfaces. In all slaughterhouses visited poultry, practice the slaughter is done manually and is not well mastered. The observations made in the killings of farms and markets helped to distinguish different categories of hygienic practices during slaughter. These practices have a significant influence on the contamination of poultry carcasses, the indicator hygiene flora and salmonella. Bleeding from these slaughterhouses is done using rarely cleaned or disinfected knife that may allow the introduction of microorganisms in the circulatory system and muscles. This same observation was made by Ch Quinet V [4] and Julie Refregier [9]. The frequent breakdown of the digestive tract is a source of carcass contamination. The manual plucking, as well as numerous contacts with the carcasses contaminated surfaces (tables, bags, knives, tea towels...) can also be at causing cross-contamination during storage operations. Fofana [1], Agence Francaise [15]showed that the waiting time for slaughter is a time when the animals are subjected to intense stress sweakens the immune facilitate the spread of germs. The highest infection rate was observed Niamakoro monitoring Boulkassoumbougou and Hamdallaye this finding may be due to the fact that in these places, slaughter occurs at inappropriate places, such as cleaning and disinfection are poorly made and facilitate the contamination of slaughter to another.

\section{Conclusion}

Poultry products (eggs and carcasses) from markets and slaughterhouses of Bamako are contaminated with
Salmonella. However, to reduce the risk of contamination of these products, apply the rules of hygiene at markets and poultry slaughterhouses; master the good practices of slaughter and poultry transportation conditions.

\section{References}

[1] Aminata Fofana, 2005 Study Report: Assessment of contamination of typhoid fever caused by the consumption of food sold in the streets of Bamako district, 68p.

[2] Anonyme. 2002. Risk assessment of Salmonella in eggs and broiler chickens WHO/FAO. Risk Assessment series microbiologiques. 1interpretive summary. pp: 7.

[3] Brewer PH, Hubert G, Morel, F. J Lemeland The non-typhoid Salmonella: clinical study ninety-one case. Sempar is Hospitals 1982; 58:915-20.

[4] Ch Quinet Vet ARSIA., 2004, plans to fight for the control of Salmonella in poultry in the field, Allée des Artisans, 25590Ciney.

[5] Hamadou ABBA, Marius K. SOMDA Ban-bo Bebanto ANTIPAS, Nicolas Barro, AlfredS. Traore, 2017. Prevalence and antibiotic susceptibility of strains of Salmonella spp. Non typhoid isolated from chicken meat in Chad.

[6] Satigui Sidibe, Coulibaly K. Sylla M, BTraore, Keita S Doumbia MR, MDiallo, Bengaly STraorek Dakouo M, MNiang, Wele CK Kone AZ, Sidibe CAK Tembely S. 2013, the dominant pathology identification poultry semiindustrialin Mali (in-urbaine peri district of Bamako and Segou and Sikasso cities: pages 431, 432.

[7] Van Immerseel In Buckj. Boyen f. Pasmans. Bertrand S. Collard J. Saegerman C. Hooyberghs J. Haeser brouck F, Ducatelle R, 2005 Salmonella in poultry and eggs, Med. Vet, 149p.

[8] ELGROUDR., F. Zerdoumi Mr. BENAZZOUZ, C. BOUZITOUNA, S Granier, A Brisabois, B. Dufour, Y Millemann, 2008, contamination of broiler by non-typhoid salmonella on farms and slaughterhouses in the Wilaya of Constantine, pp. 38-49.

[9] Julie Refregier-PETTON. Jean-Claude ALLO. Evelyn BOSCHER. Gaëlle BOURBAO. Marianne CHEMALY. Philipe FRAVALO., Marie-Odile GILLARD. Marie-José., LAISNEY. Françoise LALANDE., YOLENLe Notre Berengere Nagard., Marilyne, Stéphane Quéquiner, Marie Thérèse Gille Toquinand Salvat. 2003, Qualitative and quantitative assessment of the risk associated with slaughtering and cutting a batch of carrier turkeys Salmonella Spplivestock. Firth Poultry Research Days, Tours, 26 and 27 March 4p.

[10] Anony me. 2006a. Thecommunity Summary Report on trends and sources of zoonoses, zoonotic agents, antimicrobial resistance and food out breaks in the European Union in 2005, The EFSA Journal, 94 pp: 234.

[11] Vanesa Garcia, Xenia Vazquez, Margarita Bances, Laura Herrera-Leon, Silvia Herrera-Leon, and Rosario Rodicio. 2018, Molecular characterization of salmonella enteric Serovar Enteritidis, Geneticbasis of antimicrobial Drug Resistance and Plasmid Diversity in Ampicillin- Resistant Isolates. 
[12] WHO (world Health organization). 2015. WHO Estimates of the Global Burden of Food borne Diseases: Food borne Disease Burden Epidemiology reference Group 2007-2015. Geneva: World Health Organization.

[13] EFSA (Europen Food Safety Authority) and ECDC (European Center for Disease prevention and control). 2017. The European Union summary report on trends and sources of zoonoses, zoonotic agents and food-borne out breaks in 2016.

[14] CDC, 2000. Salmonellosis associated with chicks and Duckling Michigan and Missouri, spring1999. MMWR, 49 (14).

[15] Agence Francaise de sécurité sanitaire des aliments. 2008, Inventaire des salmonella d'origine non humaine-2006. Maison Alfort.
[16] Delarocque Astagneau E, Desenc Los J. C, Bouvet P, P. A. D. Grimont P. A. D. 1998, risk factors for the occurrence of sporadic Salmonella enterica serotype enteritidis infections in children in France: a national case control study. Epidemiol, infect, 121: 561-567.

[17] KJ. Coulibaly, S Bakayoko, K. E. Coulibaly, GT Karou, G. B. Goualie, L. Akesse, CGbono, C. Boni Cisse, K. S Koffi, E. Ekaza, A. N' doubaet M. Dosso. 2010, Biodiversitédes Salmonellaà Abidjan: Étudedesisolatsde 2003à 2009 parlecent rederéférencedel' Institut Pasteur. 